Original Research Paper

\title{
Distress About Covid-19 in Panama: Psychometric Structure
}

\author{
${ }^{1,2}$ Ericka Matus, ${ }^{3}$ Lorena Matus, ${ }^{4}$ Ana Florez, ${ }^{5}$ Ana Toriz, ${ }^{6}$ Alfredo Cuevas and ${ }^{1,2}$ Jay Molino \\ ${ }^{1}$ Faculty of Biosciences and Public Health, Universidad Especializada de las Américas, Paseo Albrook, O0629 Panamá, Panamá \\ ${ }^{2}$ Sistema Nacional de Investigación (SNI), SENACYT, Panamá \\ ${ }^{3}$ Department of Psychology, Universidad Iberoamericana, Ciudad de México, México \\ ${ }^{4}$ Faculty of Psychology, Universidad Latina de Panamá, Av. Ricardo J. Alfaro, Panamá, Panamá \\ ${ }^{5}$ Faculty of Accounting and Administration, Universidad de Panama, El Cangrejo, Av. Simón Bolívar, Panamá, Panamá \\ ${ }^{6}$ Federal Educational Authority in Mexico City, Secretariat of Public Education, Interior Circuit Ocampo. 91, \\ Tlaxpana 11370 Ciudad de México, México
}

Article history

Received: 16-09-2021

Revised: 09-10-2021

Accepted: 08-10-2021

Corresponding Author:

Jay Molino

Faculty of Biosciences and

Public Health, Universidad

Especializada de las Américas

Email: jay.molino@udelas.ac.pa

\begin{abstract}
The psychological impact of the pandemic has established the urgent need to respond to the needs of the population in each culture, region and context. Thus, in the Republic of Panama, the efforts of numerous specialists have combined actions to attend to the crisis. This study aims to obtain the factor structure and psychometric properties of the SARS-CoV-2 distress scale, which, together with eight other questionnaires, make up the battery to measure the psychological and behavioral consequences of the health crisis, based on the COVID Stress global survey initiative. We employed a non-probabilistic sample of 765 Panamanian adults who responded entirely online during the lockdown stage in March. The instrument is composed of 24 items that proved to be valid and reliable for the Panamanian sample. The main findings show that distress is linked to uncertainty and the financial situation and not due to health or education. In addition, single men with less schooling have higher levels of uncertainty and distress in general.
\end{abstract}

Keywords: Distress, COVID-19, Panama, Pandemic, Scale

\section{Introduction}

Distress is understood as a complex and intense feeling of displeasure, discomfort and fear associated with a given situation, where psychological processes allow anticipating an imminent danger or not, triggering a reaction of physical and psychological alarm, which can paralyze the body, although in temporality is of shorter duration than distress or stress.

Distress is understood as a complex and intense feeling of displeasure, discomfort and fear associated with a given situation, where psychological processes allow anticipating an imminent danger or not, triggering a reaction of physical and psychological alarm, which can paralyze the body, although in temporality is of shorter duration than distress or stress. Introduction distress is understood as a complex and intense sensation of displeasure, discomfort, as well as fear associated with a given situation, where psychological processes allow anticipating an imminent danger or not, triggering a reaction of physical and psychological alarm, which can paralyze the body. However, in temporality it is of shorter duration than distress or stress.

The present study aimed to obtain the factorial structure and psychometric properties of the SARS-CoV-2 distress scale for the Panamanian population during the pandemic, following the ethical considerations of the Declaration of Helsinki (World Medical Association Declaration of Helsinki, 1964).

On the other hand, Gómez-Salgado et al. (2020), conducted a study to identify risk factors associated with distress in a sample of 4180 Spanish participants aged 18 years or older, distributed in 50 provinces and two small Spanish autonomous cities located in North Africa. Data collection was carried out during confinement by sanitary decree.

To support the research, Gómez-Salgado et al. (2020) compiled a series of worldwide studies on distress and covid-19. Among the risk factors associated with distress, they highlight the supply of necessities, quarantine, negative health perception, degree of risk control and risk perception. Concerning gender, the reviewed works are contradictory. They report that psychological distress in Iran is higher than in the population of China; they also show that the Italian population reached high and very high levels of distress, especially in those with a history of stressful situations or medical problems 
(Gómez-Salgado et al., 2020).

They also mention that the psychological distress associated with the pandemic health crisis is estimated at $38.2 \%$ of the population suffering from a mental disorder in European countries.

The authors suggest designing preventive programs to care for distress in a pandemic situation (Gómez-Salgado et al., 2020).

Regarding risk and protective factors for psychological distress in the general population, Mazza et al. (2020) administered a national online survey to 2766 Italian participants, applied the Depression, Distress and Stress Scale (DASS-21), as well as the Personality Inventory for Adults (PID-5-BF).

The results indicate that female gender, negative affect, detachment and medical problems identify those most vulnerable to psychological distress.

At the onset of the pandemic, Petzold et al. (2020) published research on risk, resilience, psychological distress and distress in Germany. The sample had 6,509 respondents to an online survey from March 27 to April 6 on 2020 .

The results show that more than $50 \%$ expressed anxiety, distress and psychological problems due to the COVID-19 pandemic. They also found that fears were directed toward social networks and that the majority expressed fear for the health of their family members, the social consequences of the pandemic so that they caused more concerns than economic ones.

The first large-scale national survey on psychological distress in the general population due to the COVID-19 pandemic was developed in China, which was measured through a self-report questionnaire to calculate the index of traumatic distress, named COVID-19 Peritraumatic Distress Index (CPDI) by Qiu et al. (2020). The objective was to identify the prevalence and severity of psychological distress in a sample of 52,730 individuals from 36 provinces, autonomous regions and municipalities.

The CPDI incorporated the frequency in specific symptoms and disorders of distress, depression, specific phobias, stress, cognitive change, avoidance, compulsive behavior, physical symptoms and loss of social functioning in the previous week, with 24 items that conform to four dimensions: Negative mood, changes in behavior and cognitive skills, fatigue and hyperactivity and somatization (Petrozzi et al., 2020).

The findings suggest distress disorder, panic and depression. Qiu et al. (2020) recommend attention to vulnerable groups, access to the health system with medical resources, strategic planning and the national coordination of psychological first aid and a prevention and intervention system that includes epidemiological monitoring, screening and referral to reduce psychological distress to prevent further mental health problems.

In the case of Australia, Rahman et al. (2020) showed an investigation on the psychological factors associated with distress, fear and coping strategies during the COVID-19 pandemic with a sample of 587 participants.

The results indicate that being female, being 60 years of age or older, being a worker, or providing a front-line or essential service were associated with a higher level of psychological distress. Additionally, a significant association was found between increased smoking and alcohol consumption and greater psychological distress.

Concerning the work developed by Moreno Proaño (2020), it is highlighted that intolerance to uncertainty is an extreme and uncontrollable concern related to internal cognitive factors that generate distress when unable to address the causes or propose alternative solutions.

Meanwhile, Robles et al. (2021), in their work on conflicts in the face of confinement by Covid-19, highlight the category of economic problems divided into three areas, concern for the national economy, family budget adjustment and personal monetary concerns. They point out the perception that the decision-makers are the International Monetary Fund and the World Bank, so citizens are not in control of their finances. In addition, the closure of activities, personnel cuts and salary reductions are a constant.

This document aims to describe the level of distress across the adult population in times of Covid-19 in Panama.

\section{Methods}

\section{Population}

An online survey was conducted to which 765 participants responded, adults over 18 years of age, residents of the Republic of Panama. However, only 638 were considered who answered the instrument entirely. A nationwide campaign was launched through social networks such as Facebook, Twitter, WhatsApp and emails to invite the public to answer the instrument, giving a purposive, snowball sampling between May 10 and 31, 2020.

\section{Instrument}

The instrument consists of 24 questions distributed in 5 factors: Uncertainty (7 items), social relationships (4 items), adaptability (6 items), family relationships (5 items) and personal economy ( 2 items). The response options were six: Strongly disagree, disagree, slightly disagree, slightly agree, agree, strongly agree.

\section{Results}

The population was composed of $75.1 \%$ (480) men and 
$24.6 \%$ (158) women; with respect to age groups, $19.1 \%$ (122) were under 20 years old, $27.6 \%$ (176) between 21 and 30 years old, 24\% (153) between 31 and 40, 19.7\% (126) between 41 and 50, 8.5\% (54) between 51 and 60 and $1.1 \%$ (7) over 60 years old.

Regarding marital status, $51.9 \%$ (333) said they were single, widowed, or divorced and $48.1 \%$ (305) were married or in a couple.

Of the population that answered the questionnaire, 94.2\% (601) reported having university studies and $5.8 \%$ (37) did not. The employment status of the sample was composed of $46.1 \%$ (294) employed full time, $4.1 \%$ (26) employed part-time, $11.8 \%$ (75) entrepreneurs, $10.5 \%$ (67) unemployed, $6.1 \%$ (39) retired and $21.5 \%$ (137) students. Whereas $75 \%$ of the 638 participants slightly agreed to strongly agree that they felt distressed in the current coronavirus situation. The results are summarized in Table 1.

Among the responses with higher mean values and corresponding standard deviation measured independently are items 14: Greater distress in the current situation because of friends or relatives living far away $(\mathrm{M}=4.70, \mathrm{SD}=1.30)$; item 10: The national economy $(\mathrm{M}=4.70, \mathrm{SD}=1.33)$; item 12: Myself or others I know contracting the coronavirus $(\mathrm{M}=4.68, \mathrm{SD}=1.40)$; item 13 : The risk of myself or others
I know being hospitalized or dying from the coronavirus $(\mathrm{M}=4.51, \mathrm{SD}=1.57)$; item 4 : Future job prospects $(\mathrm{M}=4.32, \mathrm{SD}=1.66)$; item 23 : Not knowing how long measures such as social distancing or closing of stores, schools, restaurants will be in effect $(\mathrm{M}=4.22$, $\mathrm{SD}=1.53)$; item 1 : My current daily income $(\mathrm{M}=4.01$, $\mathrm{SD}=1.82)$. The rest of the items on the feeling of distress resulted in a range of responses from disagreeing to slightly disagree.

The items were then grouped into five distress factors (Table 3: Psychometric structure). The most surprising findings are those corresponding to the area of personal economy $(\mathrm{M}=4.16, \mathrm{SD}=1.42)$, followed by the uncertainty generated by Covid-19 $(\mathrm{M}=4.13, \mathrm{SD}=1.04)$, own adaptive capacity, $(\mathrm{M}=3.68, \mathrm{SD}=1.11)$ their social relationships $(\mathrm{M}=3.31, \mathrm{SD}=1.24)$ and finally their family relationships $(\mathrm{M}=3.01, \mathrm{SD}=1.21)$.

Although no statistically significant differences were found by sex, age, schooling, marital status, or employment status, a trend can be seen where men $(\mathrm{M}=3.66)$, people under 20 years of age (3.76), those with at least 9 years of education (4.05), single people (3.68) and students (3.80) obtained the highest score in each of the sociodemographic variables for the general scale of distress.

Table 1: Response percentages per item

\begin{tabular}{|c|c|c|c|c|c|c|c|c|c|}
\hline \multirow{3}{*}{$\begin{array}{l}\text { Questions } \\
\text { In the current situation, how much do you } \\
\text { agree that you do feel distressed over }\end{array}$} & \multirow{2}{*}{\multicolumn{7}{|c|}{ Percentages }} & \multirow{2}{*}{\multicolumn{2}{|c|}{ Descriptive }} \\
\hline & & & & \multirow[b]{2}{*}{$\begin{array}{l}\text { Slightly } \\
\text { disagree (3) }\end{array}$} & \multirow[b]{2}{*}{$\begin{array}{l}\text { Slightly } \\
\text { agree (4) }\end{array}$} & \multirow[b]{2}{*}{$\begin{array}{l}\text { Agree } \\
(5)\end{array}$} & \multirow[b]{2}{*}{$\begin{array}{l}\text { Completely } \\
\text { agree }(6)\end{array}$} & & \\
\hline & $\begin{array}{l}\text { Does not } \\
\text { apply }(0)\end{array}$ & $\begin{array}{l}\text { Strongly } \\
\text { disagree (1) }\end{array}$ & $\begin{array}{l}\text { Disagree } \\
(2)\end{array}$ & & & & & M & SD \\
\hline 1. My day-to-day income right now & 6.9 & 5.2 & 11.6 & 7.2 & 18.9 & 26.3 & 24.1 & 4.01 & 1.82 \\
\hline 2. Being able to perform my work well enough & 5.9 & 7.2 & 12.3 & 5.1 & 19.8 & 35.4 & 14.2 & 3.89 & 1.75 \\
\hline 3. My children's education & 26.4 & 10.3 & 9.8 & 3.3 & 11.9 & 20.4 & 17.9 & 2.97 & 2.33 \\
\hline 4. Future job prospects & 5.1 & 3.1 & 8.3 & 6.1 & 18.1 & 34.2 & 25.1 & 4.32 & 1.66 \\
\hline $\begin{array}{l}\text { 5. Access to everyday necessities like food and } \\
\text { other grocery items }\end{array}$ & 2.3 & 7.8 & 13.1 & 8.1 & 23.7 & 29.3 & 15.6 & 3.93 & 1.61 \\
\hline 6. Not being able to take part in social activities and occasions & 3.6 & 11.7 & 17.6 & 9.7 & 21.8 & 23.4 & 12.2 & 3.53 & 1.71 \\
\hline 7. Not being able to take part in religious activities & 6.7 & 18.6 & 17.5 & 10.5 & 17.5 & 20.4 & 8.9 & 3.10 & 1.82 \\
\hline 8. Coping with the behavior of adults who I am in isolation with & 8.0 & 12.5 & 17.9 & 10.5 & 20.4 & 18.7 & 12.0 & 3.27 & 1.83 \\
\hline $\begin{array}{l}\text { 9. Coping with the behavior of children under } \\
12 \text { who I am in isolation with }\end{array}$ & 20.4 & 17.8 & 8.3 & 7.6 & 1.6 & 13.4 & 6.9 & 2.26 & 1.97 \\
\hline 10. The national economy & 2.0 & 3.6 & 6.4 & 4.8 & 14.0 & 32.1 & 37.0 & 4.70 & 1.51 \\
\hline 11. Civil services like police, sanitation, etc. & 4.1 & 6.6 & 10.8 & 10.8 & 29.0 & 28.5 & 10.3 & 3.81 & 1.56 \\
\hline $\begin{array}{l}\text { 12. The risk of myself or others I know } \\
\text { catching Coronavirus }\end{array}$ & 1.4 & 3.4 & 3.4 & 8.7 & 17.3 & 32.0 & 33.7 & 4.68 & 1.40 \\
\hline $\begin{array}{l}\text { 13. The risk of myself or others I know } \\
\text { getting hospitalized or dying from Coronavirus } \\
\text { 14. Worry over friends or relatives, who }\end{array}$ & 2.2 & 4.5 & 7.3 & 5.9 & 18.6 & 28.5 & 32.9 & 4.51 & 1.57 \\
\hline live far away & 0.8 & 3.6 & 4.7 & 5.0 & 17.0 & 39.5 & 29.5 & 4.70 & 1.33 \\
\hline 15. Having to adapt my work to digital platforms & 6.6 & 13.3 & 19.5 & 9.8 & 17.6 & 21.4 & 11.9 & 3.30 & 1.82 \\
\hline 16. Having to adapt my social life to digital platforms & 2.0 & 10.8 & 22.0 & 10.9 & 18.9 & 22.6 & 12.8 & 3.53 & 1.67 \\
\hline $\begin{array}{l}\text { 17. Feeling ashamed acting differently towards } \\
\text { other people (e.g., at work, if out shopping) }\end{array}$ & 3.4 & 20.1 & 29.2 & 13.4 & 14.4 & 14.0 & 5.5 & 2.79 & 1.60 \\
\hline 18. Loneliness & 4.2 & 19.0 & 27.3 & 15.4 & 13.7 & 14.2 & 6.1 & 2.82 & 1.62 \\
\hline 19. How much time do I spend inside & 3.8 & 11.3 & 21.6 & 9.7 & 17.3 & 23.0 & 13.4 & 3.48 & 1.75 \\
\hline 20. How much time do I spend near others & 6.1 & 8.9 & 15.8 & 13.3 & 25.2 & 24.5 & 6.3 & 3.41 & 1.64 \\
\hline $\begin{array}{l}\text { 21. Not knowing about developments } \\
\text { related to Coronavirus }\end{array}$ & 2.8 & 9.0 & 18.1 & 11.5 & 19.7 & 27.5 & 11.4 & 3.64 & 1.65 \\
\hline $\begin{array}{l}\text { 22. Not knowing what I should do to limit } \\
\text { the spread of Coronavirus }\end{array}$ & 3.3 & 12.6 & 20.3 & 14.2 & 16.5 & 22.0 & 11.1 & 3.38 & 1.70 \\
\hline $\begin{array}{l}\text { 23. Not knowing about how long measures like social distancing } \\
\text { or closed shops/schools/restaurants will be in effect }\end{array}$ & 1.4 & 5.9 & 9.5 & 8.7 & 22.5 & 31.0 & 20.9 & 4.22 & 1.53 \\
\hline 24. Not being able to travel outside & 4.8 & 15.0 & 20.1 & 8.4 & 14.2 & 21.1 & 16.4 & 3.41 & 1.88 \\
\hline
\end{tabular}


Table 2: Correlation between factors

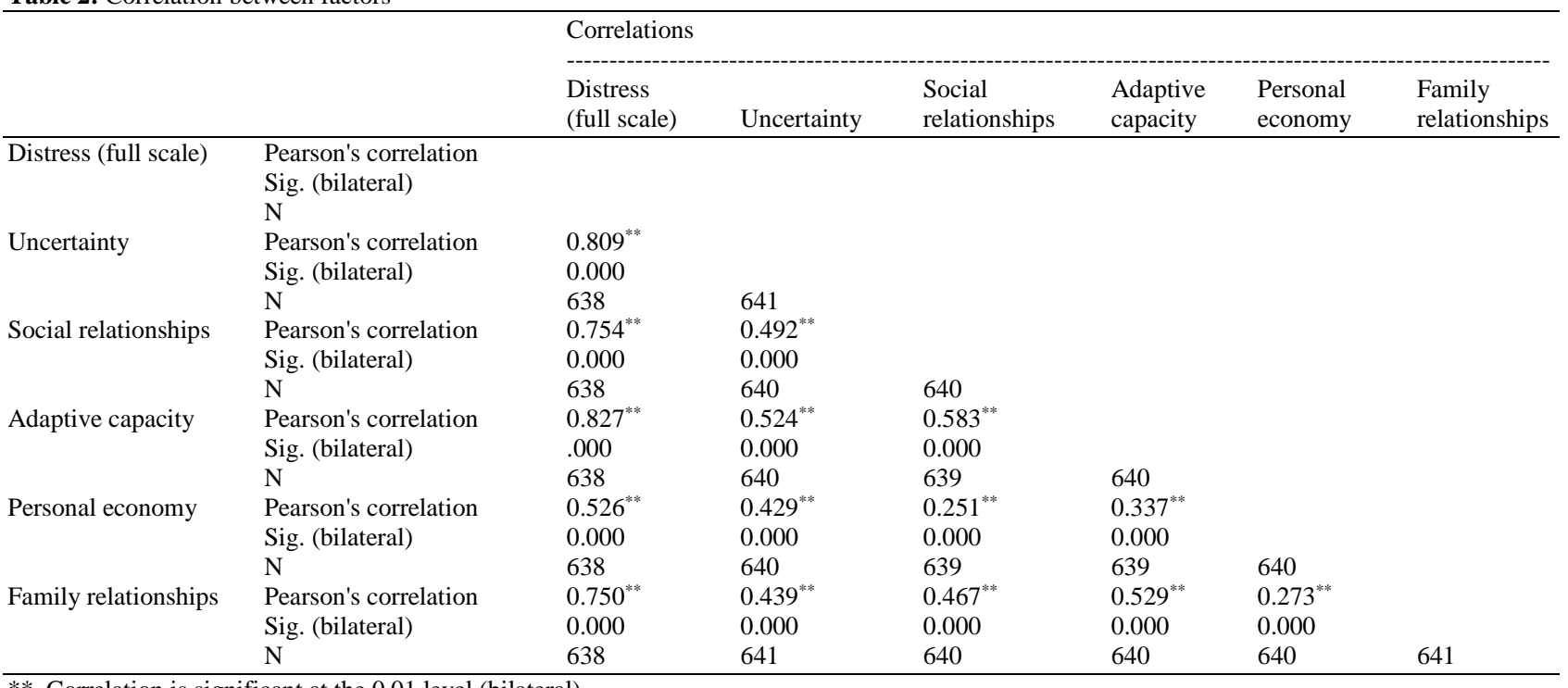

**. Correlation is significant at the 0.01 level (bilateral)

Table 3: Total percentage of variance explained in 5 factors $=51.007 \%$ and overall Cronbach's alpha $=0.880$

\begin{tabular}{|c|c|c|c|c|c|c|}
\hline Factor & Item No. & Item & $r_{i t}$ & $\begin{array}{l}\text { Factorial } \\
\text { weight }\end{array}$ & Alpha & $\begin{array}{l}\% \text { Variance } \\
\text { explained }\end{array}$ \\
\hline \multirow[t]{7}{*}{1 Uncertainty } & 12 & The risk of myself or others I know contracting coronavirus & 0.461 & 0.784 & 0.792 & 14.29 \\
\hline & 13 & The risk of myself or other people I know & & & & \\
\hline & & being hospitalized or dying from coronavirus & 0.482 & 0.729 & & \\
\hline & 10 & National economy & 0.346 & 0.655 & & \\
\hline & 23 & $\begin{array}{l}\text { Not knowing how long measures such as social distancing } \\
\text { or store/school/restaurant closures will be in effect }\end{array}$ & 0.521 & 0.596 & & \\
\hline & 21 & Learn about coronavirus-related developments. & 0.555 & 0.423 & & \\
\hline & 11 & Civilian services such as police, sanitation & 0.462 & 0.398 & & \\
\hline 2 Social & 24 & Not being able to travel outside my country & 0.335 & 0.719 & 0.675 & 10.50 \\
\hline \multirow[t]{3}{*}{ relationships } & 6 & Not being able to participate in social activities and events & 0.469 & 0.699 & & \\
\hline & 19 & How much time do I spend indoors & 0.551 & 0.581 & & \\
\hline & 18 & For the solitude & 0.560 & 0.439 & & \\
\hline 3 Adaptive & 15 & Having to adapt my work to digital platforms & 0.462 & 0.754 & 0.736 & 10.17 \\
\hline \multirow[t]{4}{*}{ capacity } & 2 & Being able to do my job well enough & 0.507 & 0.650 & & \\
\hline & 14 & Friends or relatives living far away & 0.411 & 0.461 & & \\
\hline & 20 & How much time do I spend close to other people & 0.502 & 0.423 & & \\
\hline & 8 & Dealing with the behavior of adults with whom I am isolated & 0.470 & 0.396 & & \\
\hline 4 Family & 9 & Dealing with the behavior of children under & & & & \\
\hline \multirow[t]{6}{*}{ relationships } & & the age of 12 with whom I am in isolation & 0.422 & 0.779 & 0.642 & 10.09 \\
\hline & 3 & My children's education & 0.276 & 0.710 & & \\
\hline & 7 & Not being able to participate in religious activities & 0.441 & 0.443 & & \\
\hline & 17 & Feeling ashamed to act differently towards & & & & \\
\hline & & others (e.g., at work or if going out shopping) & 0.464 & 0.435 & & \\
\hline & 5 & Access to necessities such as food & 0.509 & 0.398 & & \\
\hline 5 Personal & 1 & My current daily income & 0.300 & 0.765 & 0.492 & 5.93 \\
\hline economy & 4 & Future job prospects & 0.421 & 0.588 & & \\
\hline
\end{tabular}

On the other hand, the people who expressed feeling less vulnerability due to distress were women (3.62), those over 60 years of age (3.18), those with doctoral studies (3.22), married people (3.62) and retired people (3.31).

From Table 2 it can be understood that the highest correlations scores are resilience followed by uncertainty to the overall level of distress, while the one with the lowest score is the personal economy.

\section{Psychometric Structure}

To determine the psychometric properties of the measurement scale, a factor analysis was performed to obtain validity and Cronbach's Alpha analysis for reliability. The internal consistency is considered adequate since the Alpha score is 0.880 for the global scale.

The extraction method used was principal component analysis and the Varimax rotation method with Kaiser normalization for the factor analysis. The rotation 
converged in 7 iterations. The items that make up the conceptual factors, the weights of the factor loadings, the total correlation of corrected items $\left(r_{i t}\right)$ and the reliability of the factors are detailed in Table 3.

\section{Discussion}

During the first part of pandemic confinement, distress between the presence of the virus was evidenced by participants' perceived uncertainty. In the present study, men were shown to have a higher level of uncertainty. This could be explained by the social role they play in their families. This finding is consistent with the work of Moreno Proaño (2020), who points out that distress is due to cognitive avoidance in which people suffer from the future possibility of negative events and scenarios instead of attending to present situations; hence these distorted thoughts cause emotional discomfort. The results are also congruent with the findings of Johnson et al. (2020), who states that by not being able to predict or plan for the COVID-19 health emergency, uncertainty generates fear, helplessness, vulnerability and confusion; however, contrary to what Johnson reported, in Panama, uncertainty was more prevalent among males.

Concerning the economic area, the participants reported the highest score with an average of 4.70. Of the total, it is the females with the highest distress for this item. This result contradicts the work presented by Petrozzi et al. (2020), who state that males show greater signs of financial distress than females; however, there are some coincidences with Robles et al. (2021), in the sense that people's perception is the lack of control they have over their finances.

It is especially noteworthy that the areas corresponding to health or education showed lower values. These findings are not consistent with Petrozzi et al. (2020), who found distress about the possibility of losing one's health or that of a family member.

\section{Conclusion}

Distress is a persistent concern typified in the Diagnostic and Statistical Manual of Mental Disorders (American Psychiatric Association, 2013). The associated discomfort that is perceived causes fear of losing control and fear of feeling emotionally weak; for this reason, people try to hide their feelings of unease and unease from those around them in family, friends and work. Inappropriate management can turn into panic attacks caused by real or imagined situational or environmental variables and it appears with a prevalence in the world of between 1 and $2 \%$. It should be noted that genetic, ethnic, or substance use background could modify this percentage.

Obviously, with the specific confinement situation due to covid, the population's percentage of people with distress was exacerbated and spread. In the case of Panama, single men with less schooling present higher levels of uncertainty in particular and distress in general, which means that they are a vulnerable population and should be attended to because of their psychosocial risk implications. It is suggested to manage psychological first aid and crisis intervention remotely.

Finally, the psychometric properties of the scale used resulted in validity and reliability for Panama. Therefore, it can be freely used if the corresponding citation appears.

\section{Funding Information}

Ericka Matus and Jay Molino have also been supported by the Grant APY17-009, SENACYT, Panamá and the Grant MINBUZA-2020.926889 from the Department of European Integration, The Kingdom of the Netherlands.

\section{Author's Contributions}

Ericka Matus and Lorena Matus: Devised the main conceptual ideas and proof outline and technical details, performed numerical calculations and wrote the original draft.

Ana Florez and Alfredo Cuevas: Verified the numerical results by an independent implementation and reviewed the original draft.

Ana Toriz and Jay Molino: Supervised, visualized, reviewed and edited the manuscript, administered the project and were responsible for funding acquisition.

All authors provided critical feedback, have read and agreed to the published version of the manuscript

\section{Conflict of Interests}

The author declares that there is no conflict of interest. Funders have no role in research design, collecting, analyzing, interpreting data, writing manuscripts, or deciding to publish results. The funders had no role in the design of the study; in the collection, analyses, or interpretation of data; in the writing of the manuscript, or in the decision to publish the results.

\section{References}

American Psychiatric Association (2013). Diagnostic and statistical manual of mental disorders. DSM-5. (5th ed). Washington, D. C.

Gómez-Salgado, J. andrés-Villas, M., Domínguez-Salas, S., Díaz-Milanés, D., \& Ruiz-Frutos, C. (2020). Related health factors of psychological distress during the COVID-19 pandemic in Spain. International journal of environmental research and public health, 17(11), 3947. doi.org/10.3390/ijerph17113947

Johnson, M. C., Saletti-Cuesta, L., \& Tumas, N. (2020). Emotions, concerns and reflections regarding the COVID-19 pandemic in Argentina. Ciência \& Saúde Coletiva, 25, 2447-2456. doi.org/10.1590/1413-1232020256.1.10472020 
Mazza, C., Ricci, E., Biondi, S., Colasanti, M., Ferracuti, S., Napoli, C., \& Roma, P. (2020). A nationwide survey of psychological distress among Italian people during the COVID-19 pandemic: Immediate psychological responses and associated factors. International journal of environmental research and public health, 17(9), 3165. doi.org/10.3390/ijerph17093165

Moreno Proaño, G. (2020). Distorted thoughts and generalized anxiety in Covid-19. CienciAmérica: Revista de divulgación científica de la Universidad Tecnológica Indoamérica, 9(2), 251-255. https://dialnet.unirioja.es/servlet/articulo?codigo $=77$ 46438

Petrozzi, B. P., Arevalo-Flores, M., Krüger-Malpartida, H., \& Anculle-Arauco, V. (2020). Traducción, adaptación y validación por expertos del Indice de Distrés Peri-traumatico relacionado a la enfermedad por coronavirus 2019 (CPDI) para su uso en el Perú. https://preprints.scielo.org/index.php/scielo/preprint/ view/165

Petzold, M. B., Bendau, A., Plag, J., Pyrkosch, L., Mascarell Maricic, L., Betzler, F., ... \& Ströhle, A. (2020). Risk, resilience, psychological distress and anxiety at the beginning of the COVID - 19 pandemic in Germany. Brain and behavior, 10(9), e01745. doi.org/10.1002/brb3.1745
Qiu, J., Shen, B., Zhao, M., Wang, Z., Xie, B., \& Xu, Y. (2020). A nationwide survey of psychological distress among Chinese people in the COVID-19 epidemic: Implications and policy recommendations. General psychiatry, 33(2). doi.org/10.1136/gpsych2020-100213

Rahman, M. A., Hoque, N., Alif, S. M., Salehin, M., Islam, S. M. S., Banik, B., ... \& Cross, W. (2020). Factors associated with psychological distress, fear and coping strategies during the COVID-19 pandemic in Australia. Globalization and Health, 16(1), 1-15. doi.org/10.1186/s12992-020-00624-w

Robles, A., Junco, J., \& Martínez, V. (2021). Family and financial conflicts in university students under covid19 lockdown. Cuidarte. 10(19): 43-57. http://dx.doi.org/10.22201/fesi.23958979e.2021.10. 19.78045

World Medical Association Declaration of Helsinki. (1964). World Medical Association Declaration of Helsinki: Ethical principles for medical research involving human subjects. PMID: 24141714. 